Int. J. Electrochem. Sci., 15 (2020) $5002-5017$

\title{
Simultaneous Electrochemiluminescence Determination of Sinomenine, Cepharanthine and Tetrahydropalmatine in Stephania epigaea by Capillary Electrophoresis Coupled with Ultrasonic-Assisted Aqueous Two-Phase Extraction
}

\author{
Shuangjiao Sun ${ }^{1,2}$, Yanfen $\mathrm{Wei}^{2}$, Hao Wang ${ }^{2}$, Lifu Tang ${ }^{2}$ and Biyang Deng ${ }^{2}$ \\ ${ }^{1}$ School of pharmacy, Shaoyang University, Shaoyang 422000, China \\ ${ }^{2}$ State Key Laboratory for the Chemistry and Molecular Engineering of Medicinal Resources, School \\ of Chemistry and Pharmaceutical Sciences, Guangxi Normal University, Guilin 541004, China \\ *E-mail: dengby16@163.com
}

doi: $10.20964 / 2020.06 .33$

Received: 8 January 2020 / Accepted: 18 March 2020 / Published: 10 May 2020

\begin{abstract}
Three alkaloids in Stephania epigaea were extracted using ultrasonic-assisted extraction in an aqueous two-phase system. Based on separation by $\mathrm{CE}$ with acetonitrile as an additive, this work first established a simple and sensitive CE-ECL method for simultaneous determination of sinomenine, cepharanthine and tetrahydropalmatine in Stephania epigaea. The experimental conditions were optimized. The three alkaloids had the highest extraction rates in the aqueous two-phase system compared with the other extraction solutions studied in this paper. Under the optimized experimental conditions, the three alkaloids were optimally separated within $10 \mathrm{~min}$ and displayed linear concentration ranges for sinomenine, cepharanthine and tetrahydropalmatine of $0.08-4.0 \mu \mathrm{g} / \mathrm{mL}, 0.08-4.0 \mu \mathrm{g} / \mathrm{mL}$ and $0.04-6.0$ $\mu \mathrm{g} / \mathrm{mL}$, respectively. The detection limits of sinomenine, cepharanthine and tetrahydropalmatine $(\mathrm{S} / \mathrm{N}=3)$ were $0.027,0.024$ and $0.013 \mu \mathrm{g} / \mathrm{mL}$, respectively. This method was successfully applied for the determination of sinomenine, cepharanthine and tetrahydropalmatine in Stephania epigaea extracts with recoveries of $98.4 \%, 102.4 \%$ and $101.1 \%$, respectively.
\end{abstract}

Keywords: Capillary electrophoresis; Electrochemiluminescence; Aqueous two-phase; Ultrasonic extraction; Stephania epigaea

\section{FULL TEXT}

(C) 2020 The Authors. Published by ESG (www.electrochemsci.org). This article is an open access article distributed under the terms and conditions of the Creative Commons Attribution license (http://creativecommons.org/licenses/by/4.0/). 